\title{
The Effect of China's Family Structure on Household Nutrition
}

\author{
Yan Wang1, Thomas I. Wahl' ${ }^{1}$, James L. Seale ${ }^{2}$, J. Junfei Bai ${ }^{3}$ \\ ${ }^{1}$ Department of Agribusiness and Applied Economics, North Dakota State University, Fargo, ND, USA \\ ${ }^{2}$ Beijing Food Safety Policy \& Strategy Research Base, College of Economics and Management, China Agricultural University, \\ Beijing, China \\ ${ }^{3}$ Department of Food and Resource Economics, University of Florida, Gainesville, FL, USA \\ Email:Tom.Wahl@ndsu.edu
}

How to cite this paper: Wang, Y., Wahl, T.I., Seale, J.L. and Bai, J.J. (2019) The Effect of China's Family Structure on Household Nutrition. Food and Nutrition Sciences, 10, 198-206.

https://doi.org/10.4236/fns.2019.102015

Received: December 24, 2018

Accepted: February 15, 2019

Published: February 18, 2019

Copyright $\odot 2019$ by author(s) and Scientific Research Publishing Inc. This work is licensed under the Creative Commons Attribution International License (CC BY 4.0).

http://creativecommons.org/licenses/by/4.0/

\begin{abstract}
China's one-child policy has created entitled children or "little kings" who are spoiled by their parents and doting grandparents that want to provide the "best food" for their child to ensure the future of the family. In addition, seniors' food preferences may influence the household's diet. The extended family structure, typically including one child and seniors, will likely affect food expenditures, but does this provide the most nutritious or healthiest diet? Using household data collected from 11 Chinese cities, the results of this study suggest that the presence of a child or seniors, as well as higher income levels, and wife's education level have significant effects on healthy household food consumption.
\end{abstract}

\section{Keywords}

Chinese Food Consumption, Children, Seniors, Health, Eating Healthy

\section{Introduction}

China's one-child policy, part of China's family planning strategy, was introduced between 1978 and 1980 and formally phased out in 2015. Because of the essentially "only one child" restriction, parents want to invest in their child by providing the "best" to ensure the future of the family as well as their own retirement since children are expected to take care of parents in their old age. However, providing the "best" has created entitled children or "little emperors" who are spoiled by their parents and doting grandparents especially in extended family households that include at least one set of grandparents. Providing the "best" to children may also extend to providing too much food to the point of 
promoting obesity [1]. Dining out, especially at fast food outlets may exacerbate the obesity issue. In addition, to children affecting the food consumption behavior of households it is likely that seniors' food preferences influence the household's consumption patterns as their dietary and health concerns are accommodated. This family structure, including one child or seniors, will likely affect food expenditures as the family strives to provide the best for the child and seniors, but does this provide the most nutritious or healthiest diet?

A recently published article in The Lancet shows that China has exceeded the US in absolute number of obese population [1]. Chinese men and women contributed 16.3 percent and 12.4 percent, respectively, to global obesity in 2014 . Although these numbers did not account for China's large population base, they reflect a sharp increase since 1975 when there were only 2.1 percent of obese men and 2.5 percent of obese women living in China [1]. The increased obesity has at least partially contributed to the incidence of non-communicable diseases such as type 2 diabetes, cardiovascular diseases, and cancer [2] [3]. Noncommunicable diseases have become China's number one health threat resulting in more than $80 \%$ of the country's 10.3 million annual deaths and nearly $70 \%$ of its total disease burden [4]. The situation has become worse in recent years as more young people, especially the "little emperors", and low-income people have become obese [5] [6].

In this paper, the effect of family structure on household nutrition intake is examined. To evaluate nutrition intake, an Eating Healthy Index (EHI) is developed following the Dietary Guidelines for Chinese Residents [7], published by the Chinese Nutrition Society [8], and the Healthy Eating Index-2010 components and standards for scoring from USDA [9]. Previously, a Chinese Healthy Eating Index based upon weighted food portions was used to develop an overall healthy eating index [10]. These results may provide suggestions to guide healthier eating as well as developing recommendations to guide policymakers.

\section{Methodology}

\subsection{Data}

The Chinese Nutrition Society published the Compilation of Food-Based Dietary Guidelines in 2007 and the Dietary Guidelines for Chinese Residents in 2016. These guidelines suggest that Chinese consumers should eat a variety of foods, mainly cereals; consume plenty of vegetables, fruits and tubers; consume milk, beans or dairy- or bean-products every day; consume appropriate amounts of fish, poultry, eggs and lean meat; and reduce fatty meat and animal fat in the diet. The guidelines suggest balancing food intake with physical activity to maintain a healthy body weight and choosing a light diet that is also low in salt; if consuming alcoholic beverages, to do so in limited amounts; and avoid unsanitary and spoiled foods. The standards, popularly known as the food pagoda, for seven types of food for both 2007 and 2016 are presented in Table 1. Although similar to the 2007 guidelines, the 2016 guidelines are used in the following analysis. 
Table 1. Chinese dietary guidelines per person/day.

\begin{tabular}{ccc}
\hline Component & 2007 Guideline & 2016 Guideline \\
\hline Meat & $50 \mathrm{~g}-100 \mathrm{~g}$ & $40 \mathrm{~g}-75 \mathrm{~g}$ \\
Fruit & $200 \mathrm{~g}-350 \mathrm{~g}$ & $200 \mathrm{~g}-350 \mathrm{~g}$ \\
Vegetable & $300 \mathrm{~g}-500 \mathrm{~g}$ & $300 \mathrm{~g}-500 \mathrm{~g}$ \\
Seafood & $75 \mathrm{~g}-100 \mathrm{~g}$ & $40 \mathrm{~g}-75 \mathrm{~g}$ \\
Dairy & $\geq 300 \mathrm{~g}$ & $\geq 300 \mathrm{~g}$ \\
Grain & $250 \mathrm{~g}-400 \mathrm{~g}$ & $250 \mathrm{~g}-400 \mathrm{~g}$ \\
Eggs & $25 \mathrm{~g}-50 \mathrm{~g}$ & $40 \mathrm{~g}-50 \mathrm{~g}$ \\
\hline
\end{tabular}

To calculate an EHI, household food survey data from 2285 households in 11 cities in China were used. These cities and the survey years are: Beijing 2007; Nanjing 2009; Chengdu 2010; Xi'an, Xiamen, and Shenyang 2011; and Taiyuan, Harbin, Nanning, Taizhou, and Lanzhou 2012. The surveyed households are a stratified random sample subset of the households that participate in the Urban Household Income and Expenditure (UHIE) survey conducted by the Chinese National Bureau of Statistics. Detailed information on demographics and socio-economics of the household are also collected in the survey. See Bai et al. [11] and Bai et al. [12] for detailed information of the survey.

An EHI is developed and calculated for each family in order to assess their nutrition intake. The score for each category is calculated such that it increases if consumption is in a range representing healthy food intake. For example, if vegetable consumption is $275 \mathrm{~g}$ per day and the recommended range is between 200 $\mathrm{g}-350 \mathrm{~g}$, then the individual would receive a high score. If nutrition intake is either above or below the healthy range, the score is reduced. Consumption below the recommended range indicates low nutrition intake reducing productivity and immunity to disease, both of which have associated externalities [13]. Consumption above the recommended range may result in obesity increasing the incidence of illness or other health issues. Conceptually, the score should be somewhat like a normal distribution with the higher scores in the middle representing healthy levels of consumption and the tails representing unhealthy consumption.

The relationship between the score, representing healthy nutrition intake, and household income, wife's education level, demographics, and household composition is explored using regression analysis. The results indicate that changes in family structure have significant effects on household nutrition intake. The expectation is that when parents spend more money on food, their nutrition intake will change. If they are purchasing better quality and perhaps more nutritious food, the nutrition intake score will represent a healthy relationship. However, overeating and eating more away from home, including fast food, as incomes increase, may not be healthy. Also, when the household structure changes, the nutrition intake of household members will change, such as when there is a child born into the household. 
Based upon the Chinese Compilation of Food-Based Dietary Guidelines, this study defines the maximum points for each food as 10. Each food type $j$ has a standard range, $M_{j k}$, where $k$ is the lower or higher end of the range. For example, the lower and higher recommended levels for meat are 40 and 75 grams, respectively. If the household consumes the quantity in the recommended range, the score is 10 points, otherwise the score will decrease as follows:

$$
\begin{array}{ll}
S_{i j}=\beta \frac{Q_{i j}}{M_{j L}}, & \text { if } Q_{i j}<M_{j L} \\
S_{i j}=-\beta \frac{Q_{i j}-M_{j H}}{M_{j L}}+\beta, & \text { if } M_{j L}<Q_{i j}<\left(M_{j L}+M_{j H}\right) \\
S_{i j}=0, & \text { if } Q_{i j}>\left(M_{j L}+M_{j H}\right)
\end{array}
$$

where $S_{i j}$ represents the points that household $i$ scores and $j$ food group; $\beta$ is a constant (10); $Q_{i j}$ is the quantity that the household $i$ consumes and $j$ food group; and $M_{j k}$ is the lower $(\mathrm{L})$ and higher $(\mathrm{H})$ values of the standard range of $j$ food group.

\subsection{Model}

Based on the household data collected from the 11 Chinese cities, four indicator variables are created for child, senior, wife's education and region. Ordinary least squares (OLS) is used to estimate the relationship between score and household income, household size, and the four dummy variables to evaluate the effects on household nutrition intake as follows:

$$
S_{f}=\beta_{0 f}+\beta_{j f} H_{j f}+\beta_{m} W_{m}+\beta_{k f} D_{k f} *\left(B_{f}+R_{f}+A_{f}\right)+\varepsilon_{f}
$$

where $S_{i f}$ is the score that ith household for the $f$ th food groups, $H_{j f}$ are household characteristics including the number of household members, household income, wife's education, wife's employment status, health issues of household members, and number of times household members have dined at fast food outlets and restaurants during the survey period,. $W_{m}$ represents regional indicators for the East and West regions. $D_{k f}$ is the number of household members who are ages $k$, where $k=0-9$ years, $10-18$ years, and $60+$ years old. $B_{f}=1$ if the average consumption in the ith household for $f$ th food groups is below recommended levels, 0 otherwise. $R_{f}=1$ if the average consumption in the ith household for $f$ th food groups is in the recommended levels range, 0 otherwise. $A_{f}=1$ if the average consumption in the $i$ th household for $f$ th food groups is above recommended levels, 0 otherwise. $\varepsilon_{f}$ is an error term.

\section{Results}

Table 2 presents households divided into 3 groups by EHI: below, recommended, and above consumption levels. In each group the mean consumption level and percentage of households in the group is show in the table. The general result shows that the number of households who consume meat and eggs exceeds 
Table 2. Mean and percentage of nutrition intake by EHI group.

\begin{tabular}{cccccccc}
\hline \multirow{2}{*}{ Group } & \multirow{2}{*}{ Guideline } & \multicolumn{2}{c}{ Below } & \multicolumn{3}{c}{ Recommended } & \multicolumn{2}{c}{ Above } \\
\cline { 3 - 8 } & & Mean & $\%$ & Mean & $\%$ & Mean & $\%$ \\
\hline Grain & $250 \mathrm{~g}-400 \mathrm{~g}$ & 194 & $21 \%$ & 321 & $47 \%$ & 499 & $32 \%$ \\
Meat & $40 \mathrm{~g}-75 \mathrm{~g}$ & 21 & $4 \%$ & 65 & $9 \%$ & 201 & $87 \%$ \\
Eggs & $40 \mathrm{~g}-50 \mathrm{~g}$ & 22 & $35 \%$ & 45 & $11 \%$ & 94 & $54 \%$ \\
Seafood & $40 \mathrm{~g}-75 \mathrm{~g}$ & 13 & $48 \%$ & 57 & $21 \%$ & 138 & $31 \%$ \\
Vegs & $300 \mathrm{~g}-500 \mathrm{~g}$ & 228 & $20 \%$ & 401 & $45 \%$ & 653 & $35 \%$ \\
Fruit & $200 \mathrm{~g}-400 \mathrm{~g}$ & 83 & $44 \%$ & 268 & $21 \%$ & 646 & $35 \%$ \\
Dairy & $\geq 300 \mathrm{~g}$ & 74 & $98 \%$ & 361 & $2 \%$ & - & - \\
\hline
\end{tabular}

the recommended levels, $87 \%$ and $54 \%$ respectively, which may contribute to overweight and obesity issues. The results also indicates that eggs, seafood, fruit, and dairy consumption is below recommended levels for a significant number of households.

As shown in Figure 1, graphs of household nutrition intake scores demonstrate a normal distribution, except for dairy, which has only a minimum recommended consumption level. As previously mentioned a perfect score for each commodity is 10 for each household. The horizontal axis is daily per capita consumption in grams. The graphs clearly indicate that some households underconsume and some over-consume food. For example, according to the guidelines, healthy meat consumption should be in the range of $40-70$ grams. The graph of meat consumption clearly shows that many of the households surveyed consume more than the recommended quantities.

The regression results, shown in Table 3, indicate that the presence of children, both in the 0 - 9 and 10 - 18 age groups, have a significant positive effect for household consuming in the recommended range, but mixed effects in households consuming below and above recommended levels.

Seniors in the household have a significant positive effect on the EHI score for all foods if the household is consuming in the recommended range, but tend to have a negative effect when consuming outside of this range. The senior effect is significant for low levels of seafood and high levels of grain, meat seafood, vegetables, and fruit.

Household size has a positive effect on scores for all food categories, except dairy, suggesting that the more people in household the more carefully meals are planned resulting in more equal allocation and healthier eating.

Household income is found to have positive and significant effect on household's EHI score for meat, seafood, and dairy for consumption levels. Dairy consumption will likely increase with higher household income and result in a higher dairy score and a healthier diet.

As the wife's education level increases, the results suggest that the household EHI score will increase for all foods. When the wife has more knowledge about how to eat healthy, either due to education or experience, the household consumes 

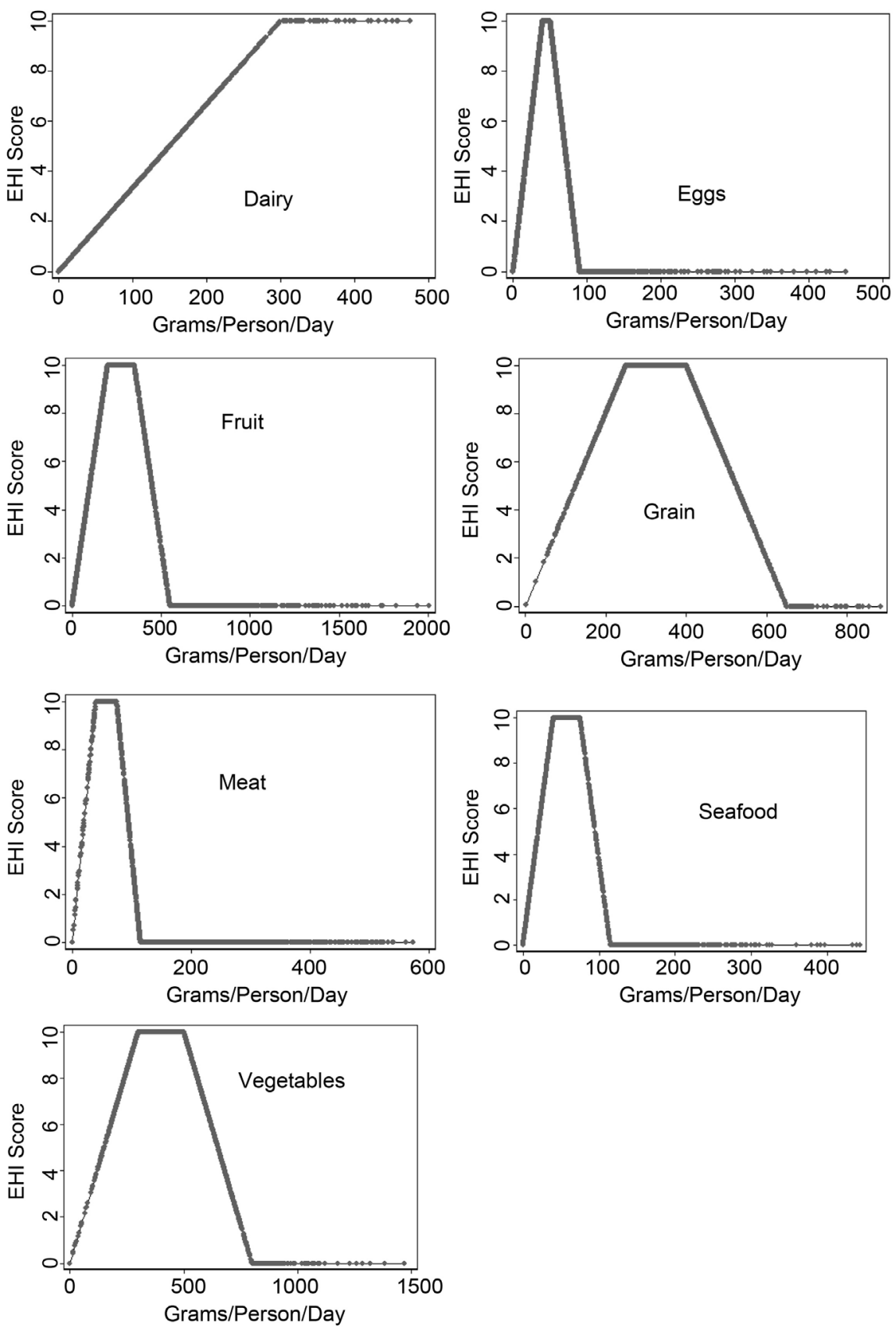

Figure 1. Eating Healthy Index (EHI) Scores calculated for consumption categories using collected survey data.

a more nutritious diet. Health issues such as hypertension, hyper glycemia, hyper lipemia, high cholesterol, lactose intolerance, or food allergies by any member of the household results in more healthy consumption scores, except for seafood and dairy. Seafood and diary consumption levels are perhaps influenced by allergic reactions since nearly $50 \%$ of seafood consumption levels and $98 \%$ of dairy consumption levels are below recommended levels.

Increased visits to fast food outlets and restaurants have a significant negative effect on meat and dairy scores, but a positive effect on vegetable scores. There 
Table 3. Regression results analyzing effects of household family structure, behavior, and region on EHI ${ }^{\mathrm{a}}$ scores.

\begin{tabular}{|c|c|c|c|c|c|c|c|}
\hline & Grain & Meat & Eggs & Seafood & Vegs & Fruit & Dairy \\
\hline \multirow[t]{2}{*}{$\mathrm{HH}^{\mathrm{b}}$ size } & 0.0829 & 0.2117 & 0.1966 & 0.2242 & 0.2705 & 0.1711 & -0.1160 \\
\hline & $(0.289)$ & $(0.018)$ & $(0.127)$ & $(0.072)$ & $(0.002)$ & $(0.166)$ & $(0.250)$ \\
\hline \multirow[t]{2}{*}{ HH income } & 0.0191 & -0.0243 & 0.0022 & -0.0628 & -0.0208 & -0.0018 & 0.0320 \\
\hline & $(0.118)$ & $(0.084)$ & $(0.912)$ & $(0.001)$ & $(0.137)$ & $(0.926)$ & $(0.043)$ \\
\hline \multirow[t]{2}{*}{ Wife's education } & 0.0258 & 0.0050 & 0.0558 & 0.2277 & 0.0318 & 0.1202 & 0.2419 \\
\hline & $(0.498)$ & $(0.909)$ & $(0.375)$ & $(0.000)$ & $(0.465)$ & $(0.047)$ & $(0.000)$ \\
\hline \multirow[t]{2}{*}{ Wife employed } & -0.0688 & -0.1619 & -0.1381 & -0.1942 & 0.0379 & -0.1042 & -0.3468 \\
\hline & $(0.478)$ & $(0.146)$ & $(0.387)$ & $(0.205)$ & $(0.732)$ & $(0.496)$ & $(0.006)$ \\
\hline \multirow[t]{2}{*}{ Health issues } & 0.2305 & 0.1114 & 0.0429 & -0.0819 & 0.0756 & 0.4714 & -0.5833 \\
\hline & $(0.006)$ & $(0.244)$ & $(0.754)$ & $(0.537)$ & $(0.427)$ & $(0.000)$ & $(0.000)$ \\
\hline \multirow[t]{2}{*}{ Fast food } & 0.0003 & -0.0030 & -0.0005 & 0.0012 & 0.0027 & 0.0008 & -0.0035 \\
\hline & $(0.649)$ & $(0.000)$ & $(0.663)$ & $(0.240)$ & $(0.000)$ & $(0.419)$ & $(0.000)$ \\
\hline \multirow[t]{2}{*}{ Restaurant } & -0.0018 & -0.0015 & -0.0001 & 0.0018 & 0.0024 & 0.0015 & -0.0022 \\
\hline & $(0.055)$ & $(0.146)$ & $(0.961)$ & $(0.211)$ & $(0.019)$ & $(0.311)$ & $(0.058)$ \\
\hline \multirow[t]{2}{*}{ City: West } & 0.1398 & -0.3335 & -0.1922 & -0.1290 & 0.0131 & -0.2410 & 1.1684 \\
\hline & $(0.250)$ & $(0.017)$ & $(0.335)$ & $(0.503)$ & $(0.925)$ & $(0.215)$ & $(0.000)$ \\
\hline \multirow[t]{2}{*}{ City: East } & 0.2888 & -0.7571 & -0.2670 & 0.7528 & 0.2001 & -0.0341 & 0.3560 \\
\hline & $(0.010)$ & $(0.000)$ & $(0.140)$ & $(0.000)$ & $(0.112)$ & $(0.846)$ & $(0.012)$ \\
\hline \multirow[t]{2}{*}{0 - 9 yrs. Below } & -0.5255 & 0.9359 & 0.3356 & -0.6181 & -0.0411 & 0.1664 & 0.2538 \\
\hline & $(0.007)$ & $(0.089)$ & $(0.241)$ & $(0.014)$ & $(0.852)$ & $(0.517)$ & $(0.103)$ \\
\hline \multirow[t]{2}{*}{0 - 9 yrs. Recom. } & 0.2266 & 2.1246 & 1.1763 & 1.1743 & 0.4365 & 1.3001 & 1.8897 \\
\hline & $(0.138)$ & $(0.000)$ & $(0.006)$ & $(0.000)$ & $(0.012)$ & $(0.000)$ & $(0.012)$ \\
\hline \multirow[t]{2}{*}{0 - 9 yrs. Above } & -0.2353 & -0.2527 & -0.1719 & -0.3646 & -0.0810 & 0.0322 & - \\
\hline & $(0.286)$ & $(0.078)$ & $(0.496)$ & $(0.227)$ & $(0.759)$ & $(0.912)$ & - \\
\hline \multirow[t]{2}{*}{10 - 18 yrs. Below } & -0.1436 & 1.4232 & 0.1402 & -0.1963 & -0.0651 & -0.0443 & 0.2984 \\
\hline & $(0.467)$ & $(0.003)$ & $(0.577)$ & $(0.362)$ & $(0.763)$ & $(0.844)$ & $(0.027)$ \\
\hline \multirow[t]{2}{*}{10 - 18 yrs. Recom. } & 0.2755 & 1.9234 & 1.1898 & 1.0709 & 0.4048 & 1.1992 & 2.7761 \\
\hline & $(0.043)$ & $(0.000)$ & $(0.002)$ & $(0.001)$ & $(0.009)$ & $(0.000)$ & $(0.026)$ \\
\hline \multirow[t]{2}{*}{10 - 18 yrs. Above } & -0.3654 & -0.1807 & 0.0110 & -0.9085 & 0.1019 & -0.1301 & - \\
\hline & $(0.028)$ & $(0.151)$ & $(0.961)$ & $(0.001)$ & $(0.610)$ & $(0.605)$ & - \\
\hline \multirow[t]{2}{*}{$60+$ yrs. Below } & -0.1646 & 0.4724 & 0.0892 & -0.2047 & 0.0813 & -0.0141 & 0.1760 \\
\hline & $(0.008)$ & $(0.000)$ & $(0.366)$ & $(0.028)$ & $(0.248)$ & $(0.881)$ & $(0.020)$ \\
\hline \multirow[t]{2}{*}{$60+$ yrs. Recom. } & 0.2486 & 1.3946 & 0.9410 & 1.0261 & 0.5469 & 1.0935 & 1.3804 \\
\hline & $(0.000)$ & $(0.000)$ & $(0.000)$ & $(0.000)$ & $(0.000)$ & $(0.000)$ & $(0.000)$ \\
\hline \multirow[t]{2}{*}{$60+$ yrs. Above } & -0.4707 & -0.1929 & -0.2972 & -0.4221 & -0.3346 & -0.3447 & - \\
\hline & $(0.000)$ & $(0.004)$ & $(0.002)$ & $(0.000)$ & $(0.000)$ & $(0.000)$ & - \\
\hline \multirow[t]{2}{*}{ Constant } & 8.0052 & 2.0390 & 4.4100 & 2.9711 & 6.0943 & 3.0900 & 0.8399 \\
\hline & $(0.000)$ & $(0.000)$ & $(0.000)$ & $(0.000)$ & $(0.000)$ & $(0.000)$ & $(0.197)$ \\
\hline Observations & 2285 & 2285 & 2285 & 2285 & 2285 & 2285 & 2285 \\
\hline Adjusted R2 & 0.445 & 0.622 & 0.299 & 0.495 & 0.471 & 0.469 & 0.182 \\
\hline
\end{tabular}

p-values in parentheses, ${ }^{a} \mathrm{EHI}$ represents Eating H; p-values in parentheses; ${ }^{\mathrm{a}} \mathrm{EHI}$ represents Eating Healthy Index; ${ }^{\mathrm{b} H H}$ represents household. 
are significant regional differences for many of the foods. The results indicate that there are significant western and eastern regional effects for both meat (negative) and dairy (positive) while there are significant positive effects for eastern cities for grain and seafood. This may reflect the relative availability of these products in different regions.

\section{Conclusions and Future Research}

Overall, the results suggest that having a child, 0 - 9 years and $10-18$ years, in the family has an overall positive effect on healthy household food consumption of all commodities when consumption is in the range recommended by the Dietary Guidelines for Chinese Residents (2016). There is an estimated positive effect when consumption levels are below recommended levels for all foods, except grain and seafood, when there is a child in the household.

Higher household income has mixed effects on healthy eating as it tends to increase the healthy intake of dairy, but lower the healthy intake of meat and seafood. The wife's education level tends to increase healthy eating with higher education being associated with healthier intake of all foods. There are also significant regional effects in healthy food consumption. Future research of this topic may include household health insurance, a more detailed assessment of nutrition intake, and the implications for the world food markets.

\section{Conflicts of Interest}

The authors declare no conflicts of interest regarding the publication of this paper.

\section{References}

[1] NCD Risk Factor Collaboration (NCD-RisC) (2016) Trends in Adult Body-Mass Index in 200 Countries from 1975 to 2014: A Pooled Analysis of 1698 Population-Based Measurement Studies with 19.2 Million Participants. The Lancet, 387, 1377-1396. https://doi.org/10.1016/S0140-6736(16)30054-X

[2] Victora, C.G., Adair, L., Fall, C., Hallal, P.C., Martorell, R., Richter, L. and Sachdev, H.S. (2008) Maternal and Child Undernutrition: Consequences for Adult Health and Human Capital. Lancet, 371, 340-357. https://doi.org/10.1016/S0140-6736(07)61692-4

[3] Ma, L.F., Guo, H.W. and He, A.N. (2007) Analysis of the Hazards and Correlative Factors of Overweight and Obesity in community Adults. Journal of Environmental \& Occupational Medicine, 24.

[4] Mohsen, N., Wang, H.D., Lozano, R., Liang, A.D., Zhou, X.F., et al. (2014) Global, Regional, and National Age-Sex Specific All-Cause and Cause-Specific Mortality for 240 Causes of Death, 1990-2013: A Systematic Analysis for the Global Burden of Disease Study 2013. The Lancet, 385, 117-171.

[5] Popkin, B.M. (2008) Will China's Nutrition Transition Overwhelm Its Health Care System and Slow Economic Growth? Health Affairs, 27, 1064-1076.

https://doi.org/10.1377/hlthaff.27.4.1064

[6] Yan, S., Li., J., Li, S. and Zhang, B. (2012) The Expanding Burden of Cardio- 
metabolic Risk in China: The China Health and Nutrition Survey. Obesity, 13, 810821. https://doi.org/10.1111/j.1467-789X.2012.01016.x

[7] Wang, S.S., Lay, S., Yu, H.N. and Shen, S.R. (2016) Dietary Guidelines for Chinese Residents (2016): Comments and Comparisons. Journal of Zhejiang University. Science B, 17, 649-656. https://doi.org/10.1631/jzus.B1600341

[8] Chinese Nutrition Society. http://www.cnsoc.org/

[9] US Department of Agriculture (USDA) and US Department of Health and Human Services (USDHHS) (2010) Dietary Guidelines for Americans, 2010. 7th Edition, US Government Printing Office, Washington DC.

http://www.cnpp.usda.gov/dietaryguidelines.htm

[10] Yuan, Y.Q., Li, F., Dong, R.H., Chen, J.S., He, G.S., Li, S.G. and Chen, B. (2017) The Development of a Chinese Healthy Eating Index and Its Application in the General Population. Nutrients, 9, 977. https://doi.org/10.3390/nu9090977

[11] Bai, J., Zhang, C., Qiao, F. and Wahl, T. (2012) Disaggregating Household Expenditures on Food away from Home in Beijing by Type of Food Facility and Type of Meal. China Agricultural Economic Review, 4, 18-35. https://doi.org/10.1108/17561371211196757

[12] Bai, J., Wahl, T.I., Lohmar, B.T. and Huang, J. (2010) Food Away from Home in Beijing: Effects of Wealth, Time and "Free" Meals. China Economic Review, 21, 432-441. https://doi.org/10.1016/j.chieco.2010.04.003

[13] Atkin, D. (2013) Trade, Tastes, and Nutrition in India. American Economic Review, 103, 1629-1663. https://doi.org/10.1257/aer.103.5.1629 